\title{
A Interação/Atuação da Equipe do Programa de Saúde da Família do Canal do Anil com a População Idosa Adscrita ${ }^{1}$
}

\author{
MAGDA RIBEIRO DE CASTRO* \\ LILIANA ANGEL VARGAS*
}

O presente estudo foi realizado em uma comunidade em Jacarepaguá, Rio de Janeiro, onde foi implantando o Programa de Saúde da Família. Teve como objeto as ações desenvolvidas pela equipe de saúde da família do Canal do Anil aos idosos adscritos no programa, com os seguintes objetivos: distinguir as ações implementadas pela equipe das ações preconizadas pelo Ministério da Saúde; analisar se essas ações contribuem na melhoria da qualidade de vida dos idosos e identificar a valorização e importância que a equipe dispensa a esse grupo etário. É um estudo de abordagem qualitativa, que utilizou para a coleta de dados a observação participante e a entrevista semi-estruturada. Como resultado, foi possível identificar que as ações realizadas pela equipe multiprofissional contribuem para a qualidade de vida dos idosos, por meio da preocupação com medicamentos, melhora do estado geral, alimentação e preocupação com a socialização. As evidências do estudo apontam, ainda, ser necessário atentar para as questões referentes ao envelhecimento, visando à promoção da assistência para atender às reais necessidades desse grupo e o conhecimento objetivando erradicar o preconceito ainda existente.

Palavras-chave: Programa de Saúde da Família; idoso; políticas de saúde.

Recebido em: 02/07/2005.

Aprovado em: 19/09/2005. 


\section{Introdução}

Neste estudo associamos o cuidado ao idoso e à estratégia de reorientação do modelo assistencial proposta pelo PSF, que tem como objetivo específico prestar, na unidade de saúde e no domicílio, assistência integral, contínua, com resolubilidade e boa qualidade às necessidades de saúde da população adscrita (BRASIL, 1998). Cabe destacar que, nesse caso, o termo integral visa a superar a dicotomia entre o modelo preventivo e o modelo curativo, que prevaleceu nas políticas de saúde ao longo da história. Porém, os novos rumos na política de saúde no Brasil, a partir da VIII Conferência Nacional de Saúde, permitiram vislumbrar, pelo menos na teoria, um panorama mais otimista enquanto possibilidade de se alcançar a integralidade das ações de saúde.

A nova estratégia de atenção é dirigida não somente à cura e à prevenção de doenças, mas, sobretudo, voltada para promover a saúde e incrementar a qualidade de vida, valorizando o papel dos indivíduos no cuidado com sua saúde, de sua família e da comunidade. Cabe à equipe de profissionais de saúde executar, de acordo com sua qualificação, os procedimentos de vigilância e promoção da saúde nas diferentes fases do ciclo da vida: criança, adolescente, adulto e idoso; e, ainda, prestar assistência integral à população adscrita, respondendo à demanda de forma contínua e racionalizada, dentre outras atribuições.

A partir do exposto, questionamos se a equipe de saúde da família participa ativamente na melhoria da qualidade de vida dos idosos, atentando, portanto, para os aspectos físicos considerados normais, para os fatores de riscos aos quais essa população está exposta e se a equipe trabalha com a família, a fim de manter o idoso o mais contextualizado possível, evitando sua exclusão familiar e social.

A questão central que norteou o estudo é: a equipe do Programa de Saúde da Família do Canal do Anil contempla as ações preconizadas no programa ao que se refere às propostas de atendimento ao idoso? Objetivando responder a essa questão, estudamos as ações desenvolvidas pela equipe do PSF junto à população idosa nele adscrita, com os seguintes objetivos: distinguir as ações implementadas pela equipe do PSF no Canal do Anil voltadas à população idosa adscrita das preconizadas pelo Programa de Saúde da Família do Ministério da Saúde; analisar se essas ações contribuem para a melhoria da qualidade de vida dos idosos e identificar a valorização e a importância que a equipe dispensa a esse grupo etário. 
A pesquisa se justifica pela existência do fenômeno denominado transição demográfica, responsável pelo aumento significativo da população idosa. Nesse sentido, torna-se imprescindível que os profissionais da saúde estejam sensíveis a prestar uma assistência adequada a essa população, atuando, portanto, na melhoria da qualidade de vida, entendendo o idoso como um ser único, com peculiaridades, sem perder de vista seu contexto familiar e social.

\section{A Comunidade do Canal do Anil}

A comunidade está localizada no bairro de Jacarepaguá, Rio de Janeiro, e pertence à área de planejamento 4.0. Apresenta condições precárias de saneamento básico, carência de recursos diversos, como acesso e transporte, e moradias em condições insalubres.

O PSF do Canal do Anil, implantado em 1999, conta com a atuação de duas equipes de saúde, atendendo ao preconizado pelo Ministério da Saúde (MS). Cada equipe é composta por um médico generalista ou médico de família, um enfermeiro, um auxiliar de enfermagem e seis agentes comunitários de saúde, os quais devem residir na área de atuação. Dessa forma, a equipe atua com um total de 18 profissionais.

Em dados coletados através do recadastramento de famílias ocorrido de dezembro de 2002 a janeiro de 2003, verificou-se que o número de habitantes estimado na comunidade em questão era de 8.042 pessoas, distribuídas em 2.511 famílias. Dependendo do número de famílias vinculadas ao programa, uma unidade de saúde da família pode atuar com uma ou mais equipes de profissionais, de acordo com a demanda e as características da organização dos serviços de saúde local. Recomenda-se que uma equipe seja responsável por uma área onde residam de 600 a mil famílias, com limite de, no máximo, 4.500 habitantes.

\section{O PSF na Política de Saúde do Brasil}

O Ministério da Saúde vem assumindo o desafio de colocar em prática seu plano de ações e metas prioritárias. Nesse contexto se insere o Programa de Saúde da Família, como caminho possível no processo de reorganização da atenção básica em saúde, carregando um enorme potencial para dar concretude - como pretendido nos princípios do SUS - à participação da comunidade e à integralidade das ações. 
Instituída em 1994 pelo MS, a estratégia utilizada pelo PSF visa à reversão do modelo assistencial vigente. Por isso, sua compreensão só é possível através da mudança do objeto de atenção, forma de atuação e organização geral dos serviços, reorganizando a prática assistencial em novas bases e critérios (BRASIL, 1998, p. 7-8).

No novo modelo que reorienta a atenção básica, é possível conhecer a realidade das famílias pelas quais a equipe do PSF é responsável, por meio do cadastramento destas e do diagnóstico de suas características sociais, demográficas e epidemiológicas; identificar os problemas de saúde prevalentes e situações de riscos às quais a população está exposta; elaborar, com a participação da comunidade, um plano local para enfrentamento dos determinantes do processo saúde-doença; e assumir o compromisso de fazer com que a saúde seja reconhecida como um direito de cidadania e, portanto, expressão de qualidade de vida, dentre outras ações.

Vale ressaltar que o PSF não se enquadra na concepção usual dos programas concebidos pelo MS, por não se tratar de intervenção vertical e paralela às atividades dos serviços de saúde; pelo contrário, fundamenta-se em estratégia que possibilita a integração e promove a organização das atividades em um território definido, como propósito de resolução dos problemas de saúde em nível individual e coletivo, considerando as ações em nível de trabalho multi e interdisciplinar e, quando necessário, articulações em nível intersetorial.

No PSF, a "família" passa a ser objeto fundamental da atenção, entendida a partir do ambiente onde vive, que, mais do que delimitação geográfica, é o espaço onde se desenvolvem as lutas pela melhoria nas condições de vida.

\section{A Valorização da Família nas Políticas de Saúde}

A preocupação e a priorização da intervenção no nível da família como forma de integração e dinamização das diversas políticas sociais vêm ganhando força em vários países. O ano de 1994 foi definido pela Organização das Nações Unidas (ONU) como "Ano Internacional da Família". Houve também a preocupação com a família na Igreja, sendo o ano 2000 escolhido pela Igreja Católica como o "Ano da Família”. Esses movimentos refletem a priorização política e social da família.

Desde 1923, com a Lei Eloy Chaves, as políticas sociais vêm-se estruturando de forma fragmentada e, nos dias atuais, a percepção da 
fragmentação das políticas sociais propiciam o surgimento de propostas e tentativas de integração das várias ações estatais no campo social. Vem crescendo internacionalmente a visão de que as unidades de atuação "família" e "comunidade" são pontos importantes da estratégia de integração das diversas políticas sociais. Exemplo dessa estratégia de integração que mostra a valorização da família é a criação do PSF, na década de 90, pelo Ministério da Saúde, centrando a assistência na dinâmica global da família e não apenas em membros isolados.

Para Arroyo (1991) apud Vasconcelos (1999, p. 9), “o espaço da família e da comunidade ocupava papel secundário na dinâmica política de transformação da sociedade", mas após vários estudos e ocorrência de movimentos sociais, as questões relativas à família foram ganhando espaço nos debates políticos. A família é considerada atualmente a célula principal da sociedade, não podendo ser vista de forma isolada da vida social e comunitária, uma vez que ambas se inserem na dinâmica política e econômica da sociedade como um todo. É na família que o indivíduo vivencia inicialmente as relações e começa a compreender o sentido de "coletividade" e de viver em grupo, construindo valores e atitudes.

O conceito de família vem sofrendo mudanças ao longo dos séculos, em decorrência de fatores econômicos, políticos, sociais e culturais. Atualmente, a composição de família vem-se modificando com maior diversidade de arranjos familiares.

Para alguns autores, as transformações ocorridas na organização da família se devem, em grande parte, às mudanças nas relações de gênero, à crescente participação da mulher no mercado de trabalho e ao advento da contracepção medicalizada moderna, dentre outros (SACAVONE, 1995; ROMANELLI, 1997).

Segundo Ferreira (1993, p. 244), família significa "pessoas aparentadas que vivem, em geral, na mesma casa". Considerando a diversidade de sua composição, concordamos com Gaíva e Arantes (1999, p. 55), que relatam que "as sociedades contemporâneas não têm um modelo único de família". Nesse contexto, a família hoje se caracteriza pela inexistência de um modelo dominante.

Com relação aos tipos de família, notamos uma transformação crescente da família nuclear (mãe, pai, filhos) para a família alargada (mãe, pai, filhos, parentes ou amigos). Dessa forma, nos deparamos com um grande índice de 
idosos vivendo com seus familiares (filho/filha, nora/genro, netos, bisnetos etc.). A estatística desse modelo de família tende a aumentar, como reflexo da transição demográfica.

\section{O Idoso: uma abordagem social}

No Brasil, a passagem de uma situação de altas taxas de fecundidade e mortalidade, para uma de baixa fecundidade e progressiva baixa da mortalidade, tem propiciado o aumento progressivo da população idosa. O fenômeno, relacionado ao envelhecimento populacional, tem constituído preocupação emergente em nosso país, onde estudos estatísticos apontam para um grande crescimento da população idosa nos próximos anos, atingindo cerca de 32 a 33 milhões de pessoas com a faixa etária maior que 60 anos.

Tais projeções indicam transformações e mudanças na estrutura socioeconômica e político-cultural da sociedade, com reflexos diretos no setor saúde, que irá sofrer forte impacto em seu financiamento.

E, sem dúvida, há um aumento desproporcional de gastos com essa população. Como exemplo, o valor total gasto no ano de $2001 \mathrm{em}$ hospitalizações com pacientes idosos foi de R \$ 1 bilhão e 217 milhões, sendo que mais de 15\% da população idosa se internou pelo menos uma vez no mesmo ano. Estudos têm demonstrado que as hospitalizações, mesmo as de curto prazo, causam deterioração da saúde do idoso, piorando sua qualidade de vida (BRASIL, 2002). Nessa perspectiva, acreditamos serem relevantes as ações de prevenção de agravos e promoção da saúde, características do nível primário de atenção.

Para Ferreira (1993, p. 441), o termo prevenir significa "dispor com antecipação de sorte que evite dano ou mal; chegar ou fazer antes de". Segundo o livro clássico de Leavell e Clarck (1976) apud Czeresnia (1999, p. 707), a prevenção em saúde "exige uma ação antecipada, baseada no conhecimento da história natural, a fim de tornar improvável o progresso posterior da doença".

Promover significa "dar impulso a; fazer avançar; causar, originar" (FERREIRA, 1993, p. 445). Ainda citando Leavell e Clarck (1976, p. 707), promoção à saúde se define tradicionalmente de maneira mais ampla que prevenção, pois se refere a medidas que "não se dirigem a uma determinada doença ou desordem, mas servem para aumentar a saúde e o bem-estar gerais". As estratégias de promoção enfatizam a transformação das condições de vida e 
A Interação/Atuação da Equipe do Programa de Saúde da Família...

de trabalho que conformam a estrutura subjacente aos problemas de saúde, demandando uma abordagem intersetorial (TERRIS, 1990 apud CZERESNIA, 1999).

O estudo científico sobre o envelhecimento, de acordo com Netto (1996) apud Moreira (2001, p. 17),

\begin{abstract}
"ficou sempre relegado a um plano secundário, pois não havia interesse em se despender verba e tempo, em se utilizar laboratórios sofisticados, para estudar uma fase do ser vivo em que ele deixa de ser produtivo e passa a ser, muitas vezes, dependente".
\end{abstract}

Em relação ao aspecto econômico, o idoso é muitas vezes considerado uma população passiva e não-produtiva, sendo sua representatividade para os recursos do país baixa ou ausente. Sabe-se que a produtividade é de extremo interesse para uma economia capitalista, por isso tal desprezo não aconteceu somente nos estudos, mas em toda conjuntura política, econômica e social. A baixa prioridade atribuída à terceira idade nas políticas públicas (assistenciais, previdenciárias etc.) evidencia descaso com as questões específicas desse segmento populacional.

As políticas sociais no Brasil já excluem da sua abrangência os segmentos chamados produtivos, isto é, os potencialmente aptos ou em vias de entrar no mercado. No caso da terceira idade, verifica-se uma incipiente atuação do Estado, talvez pelo fato de alguns órgãos considerarem ter esse segmento baixa possibilidade de recuperação da sua força de trabalho e de existência - estando, portanto, fora das políticas sociais.

Entretanto, essa situação tem sido revertida aos poucos, através da criação de políticas e ações, tendo como participantes o poder público, idosos e comunidade. É nesse contexto histórico, identificado pelo aumento percentual do número de idosos, que essa população passa a ser objeto de preocupação crescente das sociedades capitalistas.

Netto (1996) apud Moreira (2001, p.17) destaca: "o aumento do número de idosos nas últimas décadas e o fato de grande número deles permanecer em atividade e produzindo, fizeram com que o interesse pelo estudo do envelhecimento fosse se desenvolvendo progressivamente". Assim, a velhice e suas dimensões são difundidas na sociedade pelos meios de comunicação das universidades, das sociedades científicas, de palestras, de obras publicadas, de sociedades beneficentes, estando incluídas também no discurso do Estado. 
Na área de saúde do idoso, o grande marco foi a publicação pelo Ministério da Saúde, em dezembro de 1999, da Portaria nº 1.395, que instituiu a Política Nacional de Saúde do Idoso. Essa portaria passou por intensa discussão em nível nacional, foi aprovada pela Comissão Intergestora Tripartite e, finalmente, pelo Conselho Nacional de Saúde.

O grande desafio do momento é a operacionalização de suas diretrizes dentro do contexto atual. O MS estimulou ações e iniciativas que visam à mudança do modelo assistencial à saúde do idoso, hoje centrado na doença e na internação hospitalar, para um modelo que privilegie a atenção integral ao idoso de forma mais humana, com ações de prevenção de agravos, promoção, proteção e recuperação da saúde.

Esses mecanismos contribuem para atingir o propósito basilar da Política Nacional de Saúde do Idoso, ou seja, a promoção do envelhecimento saudável, a manutenção e a melhoria, ao máximo, da capacidade funcional dos idosos, a prevenção de doenças, a recuperação da saúde dos que adoecem e a reabilitação daqueles que venham a ter sua capacidade funcional restringida, de modo a lhes garantir permanência no meio em que vivem, exercendo de forma independente suas funções na sociedade.

Acreditamos ter ainda algumas questões referentes à senilidade que precisam ser elucidadas. Dessa forma, destacamos a necessidade premente de desconstruir alguns valores edificados socialmente, dentre os quais ressaltamos a supervalorização do "novo", do jovem em detrimento do idoso, tido muitas vezes como "velho". Vale ressaltar que o termo velho, além de ter conotação pejorativa, fornece uma imagem negativa desse indivíduo, muitas vezes acompanhada pelo desrespeito.

Em Ferreira (1993, p. 292), o termo idoso está definido como "que(m) tem bastante idade; velho". Para o mesmo autor, velho significa "muito idoso; antigo; gasto pelo uso; desusado; obsoleto" (1993 p. 561). Essa definição traz uma conotação repleta de depreciação e desvalorização do idoso.

Ao contrário dessa concepção, os gerontologistas afirmam que o processo de envelhecimento começa desde o momento da concepção. A velhice é então definida como um processo dinâmico e progressivo, no qual há modificações morfológicas, funcionais, bioquímicas e psicológicas que determinam a progressiva perda da capacidade de adaptação do indivíduo ao meio ambiente, ocasionando maior vulnerabilidade e maior incidência de 
processos patológicos, que culminam por levá-lo à morte. Conclui-se, portanto, que o processo do envelhecimento não é um processo unilateral, mas a soma de vários processos, os quais envolvem aspectos biopsicossociais.

Os pesquisadores reconhecem que os avanços na ciência e na medicina contribuíram para o aumento da expectativa de vida da população (entendida a partir do número de anos, em média, que uma pessoa pode esperar viver). No entanto, a razão principal para essa ampliação está associada à elevação da qualidade do nível de vida. Apesar de muito longe do ideal, se compararmos a situação atual com a de 40 ou 60 anos atrás, percebemos melhoria nutricional, elevação dos níveis de higiene pessoal, melhores condições sanitárias em geral e, particularmente, condições ambientais no trabalho e nas residências muito mais adequadas, interferindo direta e/ou indiretamente na saúde da população.

É importante que o crescimento populacional do idoso seja acompanhado paralelamente por uma melhoria na qualidade de vida e manutenção da autonomia e independência desse indivíduo. Segundo Ferreira (1993), autonomia é a faculdade de se governar por si mesmo; direito ou faculdade de se reger por leis próprias; liberdade ou independência moral ou intelectual; propriedade pela qual o homem pretende escolher as leis que regem sua conduta. Para o mesmo autor, independência significa estado ou condição de quem tem liberdade ou autonomia, de quem procura recorrer só aos seus próprios meios, de quem se basta.

O estudo da qualidade de vida em indivíduos idosos representa um desafio dos novos tempos, exigindo o conhecimento acerca do envelhecimento, visando a uma qualidade cotidiana. No sentido amplo, Silva (1999, p. 261) apud Moreira (2001, p. 35) destaca que a qualidade de vida

\footnotetext{
"aplica-se ao indivíduo aparentemente saudável e diz respeito ao seu grau de satisfação com a vida nos múltiplos aspectos que a integram: moradia, transporte, alimentação, lazer, satisfação/realização profissional, vida sexual e amorosa, relacionamento com outras pessoas, liberdade, autonomia e segurança financeira".
}

Essa citação de Silva, num sentido amplo, relaciona qualidade de vida à saúde, visto que o conceito ampliado de saúde a designa como sendo resultante das condições de alimentação, habitação, educação, renda, meio ambiente, trabalho, transporte, emprego, lazer, liberdade, acesso e posse da terra e acesso a serviços de saúde, segundo deliberado na VIII Conferência Nacional de Saúde (1986). 
Para a manutenção da qualidade de vida e bem-estar no envelhecimento, deve-se enfatizar o "novo paradigma que considera os idosos como participantes ativos na sociedade e oferece a base para um novo enfoque na promoção de saúde" (PESSINI, 1999, p. 195) apud Moreira (2001, p. 20). Em conformidade com esse paradigma, a Política Nacional do Idoso (Lei n ${ }^{\circ} 8.842$, de 4/1/1994), apresenta em seu Artigo $3^{\circ}$, Capítulo II, o seguinte princípio: “a família, a sociedade e o Estado têm o dever de assegurar ao idoso todos os direitos da cidadania, garantindo sua participação na comunidade, defendendo sua dignidade, bem-estar e o direito à vida"; mais recentemente, temos o Estatuto do Idoso, que entrou em vigor em $1^{\circ}$ de janeiro de 2004.

\section{A Assistência ao Idoso no PSF do Canal do Anil}

O estudo descritivo, segundo Gil (2002, p. 42), tem como objetivo primordial a "descrição de características de determinada população ou fenômeno". E, segundo Minayo (1998, p. 26), o caráter exploratório é o

\footnotetext{
"tempo dedicado a interrogar-nos preliminarmente sobre o objeto, os pressupostos, as teorias pertinentes, a metodologia apropriada e as questões operacionais para levar a cabo o trabalho de campo. Seu foco fundamental é a construção do projeto de investigação".
}

Adotamos a abordagem qualitativa, por se tratar de estudo que envolve o conhecimento de uma realidade que não pode ser quantificado, estando em consonância com Minayo (1998, p. 21-22), para quem essa abordagem "trabalha com o universo de significados, motivos, aspirações crenças, valores e atitudes, o que corresponde a um espaço mais profundo das relações, dos processos e dos fenômenos que não podem ser reduzidos à operacionalização de variáveis".

Como estratégia para coleta de dados, apropriamo-nos da técnica da observação participante, cuja importância, ainda segundo Minayo (1998, p. 59), reside no fato de podermos "captar uma variedade de situações ou fenômenos que não são obtidos por meio de perguntas, uma vez que, observados diretamente na própria realidade, transmitem o que há de mais imponderável e evasivo na vida real".

A observação exigiu o uso do diário de campo, para que os dados relevantes fossem registrados imediatamente após sua observação, objetivando maior veracidade. No roteiro de observação, o alvo de atenção foram as ações 
desenvolvidas pela equipe, observando-se se estas visavam à melhoria na qualidade de vida dos idosos; a percepção dos aspectos físicos do envelhecimento pelo profissional; a percepção e orientação quanto aos fatores de riscos e/ou riscos aos quais os idosos estavam expostos e interação dos profissionais com os familiares dos idosos. Além desses itens, foi alvo de observação a interação do profissional com o idoso e como o idoso se mostrou durante o contato.

Ainda sobre a coleta de dados, utilizamos a técnica de entrevista as seguintes questões:

1. Como você define o "idoso"? Como você compreende o "processo do envelhecimento"?

2. Que ação / ações você considera importante ao atender à população idosa?

3. Na sua opinião, que estratégias poderiam ser usadas para melhorar a assistência à população idosa desta comunidade?

De acordo com Minayo (1998, p. 57), a entrevista "é o procedimento mais usual no trabalho de campo. Através dela, o pesquisador busca obter informes contidos na fala dos atores sociais". Acompanhamos as visitas domiciliares e consultas realizadas na unidade de saúde da família à população idosa, realizadas pela equipe multiprofissional - sujeito deste estudo. A coleta de dados ocorreu no mês de dezembro de 2003.

Segundo Veras (1994), "o ponto de corte que define o início da velhice não é exato e varia em ambientes e circunstâncias diferentes". Apoiadas nessa concepção, decidimos, para os propósitos deste estudo, usar a idade cronológica adotada na Política Nacional do Idoso (Lei ${ }^{\circ} 8.842$ ), considerando idoso todo indivíduo "maior de 60 anos de idade".

A amostra foi constituída por dez profissionais do PSF, assim distribuídos: oito agentes comunitárias de saúde, uma médica e uma enfermeira.

\section{Análise dos Dados}

Após a sistematização dos dados observados verificou-se que, dos dez (100\%) procedimentos observados, nove (90\%) foram visita domiciliar e somente um (10\%) foi consulta na unidade de saúde da família do Canal do Anil, com 
duração média de 17 minutos. A idade dos idosos integrantes do estudo variou entre 60 e 87 anos, e o sexo predominante foi o feminino, totalizando $90 \%$.

As ações realizadas pela equipe direcionadas à população idosa incluem várias atividades, como: preocupação com medicamentos, alimentação, bemestar, socialização e exame físico.

A preocupação com medicamentos apareceu 18 vezes, sendo evidenciada por diversas formas: orientações sobre dose e horário da medicação (6), preocupação e perguntas quanto à ingestão da medicação (6), observação dos medicamentos (4) e organização de medicamentos (2).

A preocupação com alimentação apareceu sete vezes, ficando explícita através de: perguntas sobre alimentação (3); orientações sobre dieta (2); preocupação com a alimentação do idoso (1); e dicas para uma alimentação nutritiva e saudável (1).

Surgiram ações referentes ao bem-estar do idoso, expressas através de preocupação com dor (2), observação da melhora do processo alérgico e do estado geral do idoso (2), pergunta se o idoso está melhor do problema apresentado na última visita (1), preocupação com o tratamento da hipertensão arterial (1) e preocupação com a motricidade (1).

Ações voltadas à socialização desse grupo emergiram de diversas maneiras, tais como: orientações sobre atividades sociais (3) e cidadania, tentativa de integração social de idosas (2) e a busca de atividade social (2).

No Caderno de Atenção Básica estão preconizadas as ações que devem ser consideradas ao trabalhar com idosos:

"faz-se necessário que os profissionais de saúde da rede básica participem ativamente na melhoria da qualidade de vida das pessoas idosas, abordando para tanto: os aspectos físicos considerados normais e identificando precocemente suas alterações patológicas, discutindo com a pessoa idosa sobre os fatores de riscos e neles intervindo, se necessário e, trabalhando, sempre, com a família, para manter a pessoa idosa o mais contextualizada possível, evitando sua apartação da família e da sociedade" (BRASIL, 2000, p. 31).

Ao analisarmos se essas ações apontam para melhoria na qualidade de vida dos idosos, convém ressaltar que a temática "qualidade de vida" é um fenômeno complexo que permite várias abordagens e interpretações, uma vez 
que não há consenso universal sobre seu conceito. As várias discussões sobre esse conceito giram em torno de seus indicadores, os quais podem ser classificados em objetivos e subjetivos. Como indicadores objetivos temos, entre outros, condições de saúde, aspecto do ambiente físico e qualidade da habitação; entre os subjetivos encontram-se, por exemplo, a auto-realização, boas relações interpessoais, forte crença religiosa, assim como descrição positiva do casamento e situação familiar (FERRAZ; PEIXOTO, 1997).

Segundo Neri (1993), avaliar a qualidade de vida na velhice implica adoção de vários fatores de natureza biológica, psicológica e socioestrutural. Para essa autora, vários elementos são indicadores de bem-estar na velhice: longevidade; saúde biológica; saúde mental; satisfação; controle cognitivo; competência social; produtividade; atividade; status social; renda; continuidade de papéis familiares e ocupacionais e continuidade de relações informais, como a rede de amigos.

Assim, encontramos apoio nos autores citados e acreditamos que as ações realizadas pela equipe contribuem, até certo ponto, para a melhoria da qualidade de vida dos idosos do Canal do Anil. Há uma nítida atenção às condições de saúde / doença, expressa através da preocupação com os medicamentos, melhora do estado geral, alimentação, tendo sido percebidos aspectos do ambiente físico e habitacional e realizadas intervenções oportunas. $\mathrm{O}$ relacionamento interpessoal entre equipe e idoso na maioria das vezes foi satisfatório, e a preocupação com a socialização também foi um dado que merece destaque, uma vez que constitui fonte de bem-estar e participação na sociedade, além de permitir o exercício da cidadania.

Do total da amostra, apenas quatro $(40 \%)$ profissionais atentaram para a dificuldade e deficiência visual apresentada, para a dificuldade de descer e/ ou subir degraus de escadas e associação da referida cefaléia à redução da acuidade visual, além de avaliar a visão e o lacrimejamento apresentado.

Em seis $(60 \%)$ casos foi observado que o profissional não considerou a redução da acuidade visual, a lentidão de raciocínio e a dificuldade auditiva. Dois desses idosos apresentaram dados nítidos, que não foram priorizados pelo profissional que os atendia.

Quanto aos riscos e/ou fatores de riscos aos quais o idoso está exposto, notou-se que oito (80\%) situações envolviam riscos domiciliares e, destes, apenas três $(30 \%)$ foram observados e realizadas orientações aos idosos. 
Dentre os riscos observados, destacamos casa sem ventilação/sem aeração, presença de tapetes no banheiro e presença de escadas no domicílio. Esses riscos foram observados pelo profissional e, em seguida, realizadas orientações aos idosos quanto aos riscos existentes, que na maioria das vezes não eram percebidos.

Dentre os riscos não observados pelo profissional, destacamos degraus na entrada do domicílio, batentes altos na porta de entrada e na cozinha, tijolos e tábuas desniveladas na entrada do portão, escada sem corrimão, chão com grande quantidade de buracos, degraus altos e irregulares na entrada da casa e higiene precária com grande risco de roedores.

Ao observar a interação do profissional com os familiares dos idosos, percebemos que nove (90\%) idosos estavam sozinhos no momento da visita domiciliar e da consulta na USF, sendo evidenciada uma carência nessa interação. Entretanto, havia um (10\%) idoso acompanhado e, nesse caso, houve a interação do profissional com seus familiares, no sentido de integrá-los ao cuidado e tratamento desse idoso.

Dos nove profissionais que atenderam aos nove idosos que estavam sozinhos, apenas dois (22\%) profissionais demonstraram interesse em conversar e interagir com seus familiares em momento posterior, a fim de integrar o idoso à família e vice-versa. Ficou clara a preocupação desses profissionais quanto à importância de esclarecer a família sobre a necessidade de ajudar ao idoso em suas atividades, como no preparo de alimentos e no auxílio da limpeza domiciliar.

Quanto à interação do profissional com o idoso pode-se perceber que, na maioria das vezes (70\%), essa interação se deu de forma bastante positiva, ficando clara a atenção dispensada ao idoso, a paciência para ouvi-lo, a amizade e o vínculo estabelecido entre profissional e idoso. Este item está de acordo com a ótica do PSF, que "elege como ponto central o estabelecimento de vínculos e a criação de laços de compromisso e de co-responsabilidade entre os profissionais de saúde e a população" (BRASIL, 1998, p. 7).

Do último item observado, pode-se perceber como o idoso se mostrou durante o contato com o profissional, merecendo destaque os comportamentos mais apresentados: comunicativo, feliz com a visita, descontraído e cansado. Convém destacar os principais achados do estudo, através da análise dos dados obtidos a partir da entrevista. 
A análise e interpretação dos dados estarão baseadas na categorização destes e, de acordo com Lüdke e André (1986, p. 48), "o primeiro passo na análise é a construção de um conjunto de categorias descritivas". Dessa forma, a organização do material colhido deu origem a três categorias, assim denominadas:

\subsection{A definição do idoso: um conceito longe do consenso}

Nesta categoria estão as informações da equipe acerca da definição e da compreensão do envelhecimento. Pode-se perceber, quanto à definição do idoso, que três (30\%) sujeitos do estudo não associam envelhecimento à idade cronológica. O depoimento abaixo exemplifica essa afirmação:

"Eu acho que o idoso é quando a pessoa já não tem mais noção [...]. Mas quando a pessoa é lúcida, pensa por si própria e tem condições de se deslocar independente da idade, 70 anos-80, na minha opinião ela não é idosa" (Dep. 1).

Outros sujeitos (2) compreendem a definição do idoso como algo natural e como consequiência da vida, estando em concordância com Marsico et al. (2002, p. 34), que afirmam: “os seres vivos nascem, crescem, podem se reproduzir e morrem". Nessa concepção de evolução, o processo de envelhecimento é inevitável e decorre da existência.

"Eu acho que é um processo que tem que acontecer com qualquer um, quem não envelhece é porque morreu cedo. Eu particularmente tenho um pouco de medo da velhice, porque ao lidar com pessoas de idade a gente vê a carência que eles têm, aquela coisa da família não tá muito ali apoiando, entendeu?" (Dep. 7).

Em dois discursos ficou nítida a valorização do idoso:

"O idoso para mim serve como um incentivo para o meu amanhã, porque cada passo que a gente vê deles hoje serve como experiência para que no amanhã a gente não venha a passar pela mesma coisa, então eu acho que eles para mim é (sic) um poço de experiência [...]. São pessoas que deram muito no passado e realmente precisam do máximo agora no futuro. São pessoas que são esquecidas pela sociedade" (Dep. 9). 


\begin{abstract}
"Para mim o idoso é uma coisa que não tem como você colocar em questão de valores, porque é uma coisa fantástica [...]. Eu vejo o idoso como uma peça fundamental na vida de qualquer pessoa, eu acho um crime as pessoas que abandonam um idoso [...]. Você tem que dar carinho, atenção, tem que valorizá-lo e mostrar que ele ainda é capaz" (Dep. 10).
\end{abstract}

A valorização e a importância dos idosos dessa comunidade foram constatadas em quatro profissionais, ficando nítidas apenas em dois depoimentos, em que o idoso esteve associado a um "poço de experiência" e a uma "peça fundamental na vida" do ser humano. Ainda houve discursos apontando para o descaso com a terceira idade (1), a sobrecarga a física que alguns idosos se submetem (1) e a vinculação do envelhecimento à idade cronológica (1): "Bom, ao meu ver o idoso aqui no Brasil é muito discriminado ainda..." (Dep. 5).

A discriminação a esse grupo etário confronta os princípios da Política Nacional do Idoso, que em seu Art. $3^{\circ}$, capítulo II, seção I, item III dispõe: “O idoso não deve sofrer discriminação de qualquer natureza".

Quanto à compreensão do processo do envelhecimento, dos dez sujeitos participantes (100\%), dois (20\%) não responderam a esse questionamento e um (10\%) repetiu a resposta do item anterior, que foi desconsiderada. Dessa forma, tivemos dois (28\%) discursos apontando esse processo como algo natural.

"O processo do envelhecimento é uma linha natural, todos nós se não morrermos antes vamos envelhecer [...]. A gente vê que o envelhecimento mudou hoje em dia [...] daqui para o futuro, o número de idosos e as estatísticas mostram que vão aumentar e já estão aumentando, a sobrevida está aumentando. Hoje em dia não é difícil você achar pessoas com 85-90 anos com boas condições físicas e a gente tem que se preparar para isso aî" (Dep. 6).

O depoimento acima traz um alerta importante para os profissionais de saúde, uma vez que refere que esses profissionais precisam se preparar para assistir a esse grupo populacional que vem crescendo.

Dentre os cinco (50\%) sujeitos restantes, destacam-se a associação do processo do envelhecimento ao envelhecimento físico (1); a dissociação desse processo ao envelhecimento físico (1); a associação desse processo à mente e à atividade (1); à falências (1); e, enfim, um processo deficiente (1). 


\subsection{O atendimento ao idoso no PSF: um misto de virtudes}

Esta categoria contempla as ações importantes no atendimento prestado à população idosa, cujo levantamento trouxe à tona vários sentimentos de afeição e amabilidade por parte dos sujeitos do estudo, estando o carinho em clara evidência (3). O depoimento abaixo exemplifica essa afirmação:

"Olha, eu prezo muito o carinho, sabe? Eu me identifico muito com os idosos e quando chego perto de um idoso eu passo muito carinho para ele e eu sei que eles precisam disso. Então, eu tento ao máximo dar para eles o que eu sei que eles não têm" (Dep. 9).

Também merecem destaque nesta categoria ações como: atenção (2), paciência (2), deixar o idoso falar / se expressar (2) e equipe pronta para ouvir. Estas são qualidades fundamentais para a criação de vínculos entre equipe e população, além de ser importante recuperar a auto-estima e tentar gerar uma qualidade de vida para os idosos (1).

"Eu acho que você tem que ter muita atenção e ter um olhar diferenciado" (Dep. 7).

"Paciência, é aceitar, é você estar alegre, estar bem, estar acompanhando e tolerante com eles" (Dep. 1).

"Eu tenho uma coisa, eu sempre chego na casa do idoso e deixo ele falar. Tem vezes que eles falam tanto que não me deixam falar, principalmente as pessoas que moram sozinhas. Eles têm uma necessidade muito grande de falar e principalmente lembrar o passado" (Dep. 2).

A escuta terapêutica se justifica pela necessidade que todo ser humano tem de se comunicar, de compartilhar sentimentos, idéias, expectativas e situações. O homem, como ser social, estabelece suas relações através da comunicação, que, para ser efetiva, exige a escuta.

"É, eu acho que o imprescindível é tentar gerar para ele uma qualidade de vida; é a gente justamente tentar buscar que ele recupere um pouco da autoestima que muitas vezes é perdida com aquelas coisas de que o velho não pode fazer nada...” (Dep. 6). 
Néri (1993) defende a idéia de que quanto mais participativo for o idoso, maior sua satisfação com a vida. É importante lembrar que, sentindo-se útil, o idoso continua motivado e mantém sua auto-estima.

\subsection{Melhorando a assistência: idéias em construção}

Essa categoria aborda as estratégias que podem ser usadas para melhorar a assistência ao idoso da comunidade em questão. Foram mencionadas várias atividades, com destaque para a socialização dos idosos (6).

"Acho que aqui na comunidade deveria ter condições e apoio para a gente poder reuni-los, ter encontro com os idosos, deixar eles conversarem [...]. Tirar eles um pouco de casa e deixar eles se enturmarem com idosos, crianças, adolescentes, com todo mundo" (Dep. 2).

A socialização vai ao encontro das finalidades da Política Nacional do Idoso, que em seu Art. $1^{\circ}$, capítulo I, dispõe: "A Política Nacional do Idoso tem por objetivo assegurar os direitos sociais do idoso, criando condições para promover sua autonomia, integração e participação efetiva na sociedade".

Para Gomes e Ferreira (1985), citados por Marcon et al. (1999, p. 223), "a integração e participação sociais influenciam positivamente o bem-estar psíquico e físico”. Daí a importância de os profissionais de saúde avaliarem as condições de vida do idoso e junto com ele buscarem recursos para melhorar e/ ou manter seu bem-estar, por meio de sua integração social, através de atividades que lhe proporcionem prazer e, por conseguinte, qualidade de vida.

Percebeu-se, através de alguns discursos, a necessidade de incorporar recursos humanos e parcerias à equipe do Programa de Saúde da Família do Canal do Anil (2), como explicitado no depoimento a seguir:

"No caso aqui da nossa equipe, a gente teria que ter mais pessoal para trabalhar [...] para dar uma atenção melhor. A gente tá sobrecarregado, não dá para dar uma atenção básica assim [...]. A gente procura fazer o melhor, dar o melhor da gente, mas às vezes fica muito complicado" (Dep. 5).

Ainda surgiram declarações envolvendo família, questão governamental e atuação da equipe, de forma a amenizar os problemas apresentados pelos idosos. 


\section{Considerações Finais}

É possível apontar algumas ações da equipe multiprofissional do PSF do Canal do Anil direcionadas à população idosa adscrita, envolvendo a preocupação com medicação, alimentação e socialização desses indivíduos. Essas ações contribuem, até certo ponto, para a melhoria da qualidade de vida da população, embora qualidade de vida seja um tema polissêmico, dotado de várias abordagens e interpretações.

A definição do termo idoso, na concepção da equipe, permitiu perceber a multiplicidade de idéias, ficando nítida a inexistência de um consenso acerca desse conceito. Nessa perspectiva, acreditamos que as visões diferenciadas a respeito do processo do envelhecimento interfiram na atuação desses profissionais com o grupo etário em questão.

A valorização do idoso ficou clara nos depoimentos de dois membros da equipe, estando associada a um "poço de experiência" e a uma "peça fundamental na vida" de todo ser humano.

Quanto às ações envolvidas no atendimento ao idoso, observa-se que a equipe como um todo, ao se deparar com ele, apresenta sentimentos de afeição e ações de amabilidade afloradas, expressos pelas palavras "carinho, atenção e paciência", além de se apropriar da escuta como elemento terapêutico.

Pode-se observar que a grande maioria dos profissionais (70\%) interage de forma satisfatória com a clientela idosa. Os resultados permitiram apontar, ainda, para a necessidade de desenvolver ações que visem à socialização como estratégia para melhorar a assistência ao idoso da comunidade em questão. Essa medida, além de criar condições para promover sua autonomia, integração e participação efetiva na sociedade, influencia de modo positivo seu bem-estar psíquico e físico. Cabe ressaltar que, para a adequada abordagem da pessoa idosa, faz-se necessário compreender o envelhecimento como um processo essencialmente benigno, não-patológico, sem perder de vista, entretanto, seu contexto familiar, cultural e social.

A equipe de saúde de uma unidade básica deve sempre estar atenta ao indivíduo idoso. Não na busca permanente de problemas, mas na constante atenção ao seu bem-estar, à sua rotina funcional e à sua inserção na sociedade, sendo importante abordar o idoso de forma integral e contextualizada, sem jamais deixa-lo à margem do seu contexto. 
A equipe de saúde deve estar preparada também para identificar sinais e sintomas de riscos, associados aos mais variados aspectos, incluindo a saúde mental e física do idoso e situações domiciliares e ambientais, já que é de responsabilidade da equipe, em conjunto com a família do idoso, identificar situações de riscos no domicílio, muitas delas podendo gerar acidentes, como quedas. É preciso intervir sempre que necessário, a fim de não originar consequiências desastrosas para a autonomia e independência desse idoso.

Concordamos com Meirelles (1997, p. 24), que afirma que o ser humano não pode continuar a ser visto como um produto com prazo de validade, uma determinada máquina condenada à obsolescência. A velhice nasce com o homem e é resultado de sua infância, de sua juventude, de sua maturidade, de suas experiências, de seus valores, enfim, de toda sua trajetória biológica, espiritual e social. Nesse contexto, convém nos prepararmos para interagir de modo adequado e satisfatório com esse mundo que vem se tornando grisalho.

\section{Referências}

BRASIL. Política Nacional do Idoso. Lei no 8.842, de 4 de janeiro de 1994. Brasília. 1996. Brasília.

Política Nacional do Idoso. Decreto no 1.948 , de 3 de junho de . Política Nacional de Saúde do Idoso: Portaria $\mathrm{n}^{\circ} 1.395$, de 10 de dezembro de 1999. Brasília.

. Normas para pesquisa envolvendo seres humanos. Resolução n 196 do Conselho Nacional de Saúde. MS, Brasília, 1996.

. Reduzindo as desigualdades e ampliando o acesso à assistência à saúde no Brasil. Brasília: MS, 2002.

- Saúde da família: uma estratégia para a reorientação do modelo assistencial. Brasília: MS, 1998.

Cadernos de Atenção Básica: Programa Saúde da Família.

Brasília, MS, 2000 (Caderno 3 - Educação Permanente).

CZERESNIA, D. O conceito de saúde e a diferença entre prevenção e promoção. Cadernos de Saúde Pública, v.15, p. 701-710, 1999. 
FERRAZ, A. F.; PEIXOTO, M. R. B. Qualidade de vida na velhice: estudo em uma instituição pública de recreação para idosos. Rev. Esc. Enf. USP, São Paulo, v. 31, n. 2, p. 316-338, 1997.

FERREIRA, A. B. H. Minidicionário Aurélio. Rio de Janeiro: Nova Fronteira, 1993. GAÍVA, M. A. M.; ARANTES, S. L. O cuidado da criança na família contemporânea: uma discussão de papéis. Caderno de Pesquisa Cuidado é Fundamental. Rio de Janeiro, ano III, n. 2, p. 54-64, abr.-jun. 1999.

GIL, A. C. Como elaborar projetos de pesquisa. São Paulo: Atlas, 2002.

LÜDKE, M.; ANDRÉ, M. Pesquisa em educação: abordagem qualitativa. São Paulo: EPU, 1986.

MARCON, S. S. et al. O cotidiano do idoso e suas relações familiares revelando indícios de qualidade de vida. Texto Contexto Enfermagem, Florianópolis, v. 8, n. 3, p. 213-232, set./dez. 1999.

MARSICO, M. T. et al. Novo marcha-criança. Ciências naturais: ensino fundamental: $4^{\mathrm{a}}$ série. São Paulo: Scipione, 2002.

MEIRELLES, M. E. A. Atividade física na terceira idade. Rio de Janeiro: Sprint, 1997.

MINAYO, M. C. S. Pesquisa social-teoria, método e criatividade. Rio de Janeiro: Vozes, 1998.

MOREIRA, C. A. Atividade física na maturidade. Rio de Janeiro: Shape, 2001.

NERI, A. L. Qualidade de vida no adulto maduro: interpretações teóricas e evidências de pesquisa. In: NERI. A. L. (Org.). Qualidade de vida e idade madura. Campinas: Papirus, 1993.

ROMANELLI, G. Autoridade e poder na família. In: CARVALHO, M. C. B. (org.). A família contemporânea em debate. São Paulo: Cortez, 1997.

SACAVONE, L. (Org.). Trabalho, saúde e gênero na era da globalização. Goiânia: AB Editora, 1995.

VASCONCELOS, E. M. A priorização da família nas políticas de saúde. Saúde em Debate, Rio de Janeiro, v. 23, n. 53, p. 6-19, set.-dez. 1999.

VERAS, R. P. et al. Políticas de atenção à saúde na terceira idade. Rio de Janeiro: IMS-UERJ, 1994 (Série Estudos em Saúde Coletiva, 92). 


\section{NOTAS}

* Graduada em Enfermagem pela Escola de Enfermagem Alfredo Pinto, da Universidade Federal do Estado do Rio de Janeiro (UNIRIO). Residente de Enfermagem do Ministério da Saúde / UNIRIO. Endereço eletrônico: magdacastro@ig.com.br

** Doutora em Saúde Coletiva pelo Instituto de Medicina Social, da Universidade do Estado do Rio de Janeiro (UERJ); professora adjunta no Departamento de Enfermagem em Saúde Pública da UNIRIO. Endereço eletrônico: lilianaangel@globo.com

${ }^{1}$ Este estudo surgiu como requisito para a conclusão do curso de graduação em enfermagem na Escola de Enfermagem Alfredo Pinto, da Universidade Federal do Estado do Rio de Janeiro (UNIRIO), realizado no segundo semestre de 2003. O interesse pelo tema sucedeu da experiência no Programa de Saúde da Família (PSF) do Canal do Anil, enquanto acadêmica, onde foi possível acompanhar algumas ações realizadas pela equipe multiprofissional do programa e, em especial, as ações voltadas para a população idosa nele adscrita. 
Interaction/Action by the Family Health Team with the Elderly Population in Canal do Anil, Rio de Janeiro

The current study was conducted in a community in Jacarepaguá, Rio de Janeiro, where a Family Health Program has been implemented. The study focused on the actions developed by the family health team in the Canal do Anil community with senior citizens enrolled in the program, with the following objectives: distinguish between the actions implemented by the team and those recommended by the Ministry of Health; analyze whether these actions contribute to improved quality of life for the elderly; and identify how the team values this age group. Methodology: this was a qualitative study, utilizing participatory observation and a semi-structured interview for the data collection. As results, we observed that the actions implemented by the multi-professional team contributed to the senior citizens' quality of life by means of concern for their medication, improved overall health status, nutrition, and socialization. The study's evidence further demonstrates the need to be alert to issues of aging in order to promote the proper care to meet this group's real needs and foster knowledge to eradicate persistent prejudices towards the elderly.

Key words: Family Health Program; elderly; health policies. 